\title{
Article \\ One-Pot Bi-Enzymatic Cascade Synthesis of Novel Ganoderma Triterpenoid Saponins
}

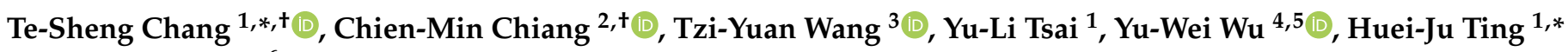 \\ and Jiumn-Yih $\mathrm{Wu}^{6, *}$
}

1 Department of Biological Sciences and Technology, National University of Tainan, Tainan 70005, Taiwan; aa0920281529@gmail.com

2 Department of Pharmacy, Chia Nan University of Pharmacy and Science, No. 60, Sec. 1, Erh-Jen Rd., Jen-Te District, Tainan 71710, Taiwan; cmchiang@mail.cnu.edu.tw

3 Biodiversity Research Center, Academia Sinica, Taipei 115, Taiwan; tziyuan@gmail.com

4 Graduate Institute of Biomedical Informatics, College of Medical Science and Technology, Taipei Medical University, Taipei 106, Taiwan; yuwei.wu@tmu.edu.tw

5 Clinical Big Data Research Center, Taipei Medical University Hospital, Taipei 110, Taiwan

6 Department of Food Science, National Quemoy University, Kinmen County 892, Taiwan

* Correspondence: mozyme2001@gmail.com (T.-S.C.); hting@mail.nutn.edu.tw (H.-J.T.); wujy@nqu.edu.tw (J.-Y.W.); Tel.: +886-6-2602137 (T.-S.C.); +886-6-2606171 (H.-J.T.); +886-82-313310 (J.-Y.W.)

+ The two authors contributed equally.

Citation: Chang, T.-S.; Chiang, C.-M.; Wang, T.-Y.; Tsai, Y.-L.; Wu, Y.-W.;

Ting, H.-J.; Wu, J.-Y. One-Pot

Bi-Enzymatic Cascade Synthesis of

Novel Ganoderma Triterpenoid

Saponins. Catalysts 2021, 11, 580.

https://doi.org/10.3390/

catal11050580

Academic Editor: Richard Daniellou

Received: 29 March 2021

Accepted: 28 April 2021

Published: 30 April 2021

Publisher's Note: MDPI stays neutral with regard to jurisdictional claims in published maps and institutional affiliations.

Copyright: (c) 2021 by the authors. Licensee MDPI, Basel, Switzerland. This article is an open access article distributed under the terms and conditions of the Creative Commons Attribution (CC BY) license (https:// creativecommons.org/licenses/by/ $4.0 /)$.

\begin{abstract}
Ganoderma lucidum is a medicinal fungus whose numerous triterpenoids are its main bioactive constituents. Although hundreds of Ganoderma triterpenoids have been identified, Ganoderma triterpenoid glycosides, also named triterpenoid saponins, have been rarely found. Ganoderic acid A (GAA), a major Ganoderma triterpenoid, was synthetically cascaded to form GAA-15-O- $\beta$ glucopyranoside (GAA-15-G) by glycosyltransferase (BtGT_16345) from Bacillus thuringiensis GA A07 and subsequently biotransformed into a series of GAA glucosides by cyclodextrin glucanotransferase (Toruzyme $^{\circledR} 3.0 \mathrm{~L}$ ) from Thermoanaerobacter $\mathrm{sp}$. The optimal reaction conditions for the second-step biotransformation of GAA-15-G were found to be $20 \%$ of maltose; $\mathrm{pH} 5 ; 60{ }^{\circ} \mathrm{C}$. A series of GAA glucosides (GAA-G2, GAA-G3, and GAA-G4) could be purified with preparative high-performance liquid chromatography (HPLC) and identified by mass and nucleic magnetic resonance (NMR) spectral analysis. The major product, GAA-15-O-[ $\alpha$-glucopyranosyl- $(1 \rightarrow 4)-\beta$-glucopyranoside] (GAA-G2), showed over 4554 -fold higher aqueous solubility than GAA. The present study demonstrated that multiple Ganoderma triterpenoid saponins could be produced by sequential actions of BtGT_16345 and Toruzyme $^{\circledR}$, and the synthetic strategy that we proposed might be applied to many other Ganoderma triterpenoids to produce numerous novel Ganoderma triterpenoid saponins in the future.
\end{abstract}

Keywords: Ganoderma lucidum; ganoderic acid A; triterpenoid; glycosyltransferase; cyclodextrin glucanotransferase; saponin

\section{Introduction}

Ganoderma lucidum is a medicinal fungus which has been used as a dietary supplement to promote healthiness in Asia for thousands of years [1]. In the modern age, many triterpenoids are purified from the fungus and identified to possess benevolent bioactivities, such as anti-cancer, antiinflammation, anti-bacteria, antioxidant, and immune-regulation activities [2]. Ganoderic acid A (GAA) is a major Ganoderma triterpenoid and recently has been shown to be bioactive on medical applications, including inhibiting bleomycininduced lung fibrosis in mice [3], attenuating lipopolysaccharide-induced lung injury in mice [4], retarding renal cyst development in polycystic kidney disease [5], and protecting neural cells against nitric oxide (NO) stress injury [6].

In addition to G. lucidum, triterpenoids were also widely distributed among plants $[7,8]$. Moreover, the plant triterpenoids naturally exist in their glycosidic forms, named 
saponins $[7,8]$. Some studies demonstrated that these triterpenoid saponins possess more bioactivities than the aglycon forms [7-10]. Studies also show that the glycosylation of small molecules increases aqueous solubility [10-13] and improves the bioavailability of the original molecules [14,15]. Given the advantages of glycosylated molecules, knowledge about glycosylation of natural products has been quickly accumulated in recent years [16-19].

On the other hand, even though more than 300 Ganoderma triterpenoids have already been identified, very few Ganoderma triterpenoid saponins have been found [20,21]. Even though it is still not clear why G. lucidum does not biosynthesize Ganoderma triterpenoid saponins in vivo, developing ex vivo biotransformation strategies to produce novel Ganoderma triterpenoid saponins with strengthened bioactivities has become an issue of interest.

In nature, glycosylation of small molecules is usually catalyzed by Leloir glycosyltransferase (GT), which uses activated sugar, such as uridine diphosphate-glucose (UDP-G), as a sugar donor to glycosylate small molecules (sugar acceptors), such as flavonoids or triterpenoids [16-19]. Until now, dozens of plant GTs [22] and seven bacterial GTs [23] have been demonstrated to catalyze the glycosylation of triterpenoids. Among them, all identified plant or bacterial GTs belong to the GT1 family, except BtGT_16345, a novel GT28 from Bacillus thuringiensis GA A07, that regioselectively catalyzes C-15 glycosylation of GAA [24]. On the other hand, due to the high cost of UDP-G, some scientists focus on finding novel enzymes that use inexpensive sugar, such as starch, dextrin, maltose, or sucrose, as sugar donors to catalyze the glycosylation of small molecules $[18,19,25]$. Most of these novel enzymes belong to either glycoside-hydrolases (GH) family 13 (GH13), such as $\alpha$-amylase (E.C. 3.2.2.1), $\alpha$-glucosidase (E.C. 3.2.1.20), amylosucrase (E.C. 2.4.1.4), and cyclodextrin glucanotransferase (E.C. 2.4.1.19), or GH 70, such as dextransucrase (E.C. 2.4.1.5) $[18,19,25]$.

As described above, producing Ganoderma triterpenoid saponins could be approached via synthetic biology. Furthermore, to the best of our knowledge, no study has attempted to produce Ganoderma triterpenoid saponins using GH enzymes yet. In the present study, three commercial and one recombinant GH13 enzymes were assayed for the ability to glycosylate Ganoderma triterpenoids using inexpensive sugar as sugar donors. Among them, cyclodextrin glucanotransferase from Thermoanaerobacter sp. (Toruzyme ${ }^{\circledR} 3.0 \mathrm{~L}$ from Novozyme company) was confirmed to catalyze the glycosylation of GAA-15-O$\beta$-glucopyranoside (GAA-15-G), which was the glycosylated product of GAA biotransformed by BtGT_16345 [24]. The catalytic conditions for Toruzyme ${ }^{\circledR}$ were optimized and the products were purified with preparative high-performance liquid chromatography (HPLC). Both the chemical structures and the aqueous solubility of the products were determined further.

\section{Results}

\subsection{Biotransformation of $G A A$}

This study investigated four GH13 enzymes for glycosylation activity toward GAA since these enzymes have been reported to possess transglycosylation activity toward either simple phenolics or flavonoids. The four enzymes included three commercial enzymes, $\alpha$-amylase from Aspergillus oryzae (Sigma 10065) [26], heat-stable $\alpha$-amylase from Bacillus licheniformis (Sigma A3306) [26], and cyclodextrin glucanotransferase (Toruzyme ${ }^{\circledR} 3.0 \mathrm{~L}$, Novozyme) [26-32], and one recombinant amylosucrase from Deinococcus geothermalis (DgAS) $[12,33,34]$. Unfortunately, none of them were found to biotransform GAA (data not shown). 
On the other hand, the four GH13 enzymes were also reported to catalyze the glycosylation of flavonoid glucosides [30,33,34], steroidal saponins [26,31], and triterpenoid saponin ginsenoside [32]; therefore, the four enzymes were re-evaluated for the ability to catalyze the glycosylation of a GAA saponin, GAA-15-G, which can be biotransformed from GAA by BtGT_16345 [24]. During our test using a one-pot reaction, GAA was first biotransformed by BtGT_16345; then, the four GH13 enzymes were added to start the second biotransformation in a one-pot reaction. We found that only Toruzyme ${ }^{\circledR}$ could biotransform GAA-15-G. Figure 1 shows the HPLC analysis of GAA (1), the first reaction product GAA-15-G biotransformed from GAA by BtGT_16345 (2), and the second reaction product GAA-G2 biotransformed sequentially from GAA by BtGT_16345 and then by Toruzyme ${ }^{\circledR}$ with $2 \%$ maltose (3).

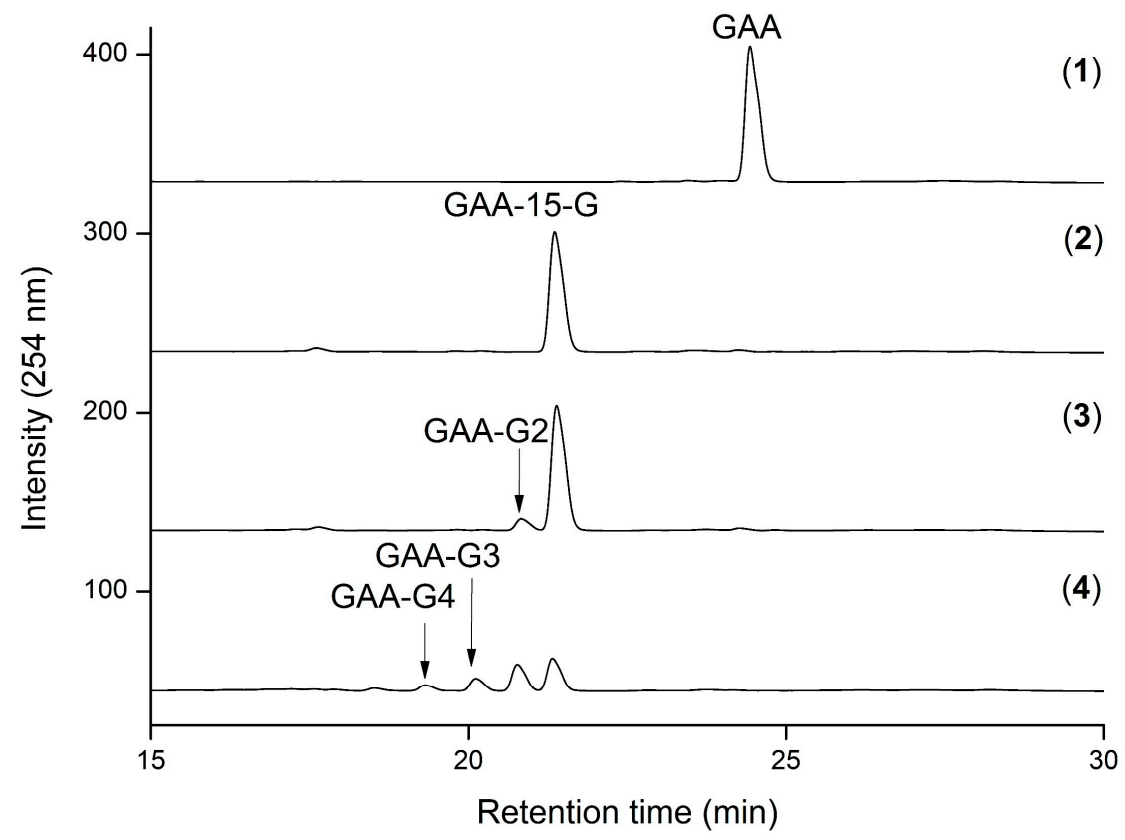

Figure 1. High-performance liquid chromatography (HPLC) analysis of the biotransformation products of ganoderic acid A (GAA) by Bacillus glycosyltransferases (GT), BtGT_16345 and Thermoanaerobacter cyclodextrin glucanotransferase $\left(\right.$ Toruzyme $^{\circledR} 3.0$ L). (1) GAA only. (2) Biotransformation product of GAA by BtGT_16345 at $30^{\circ} \mathrm{C}$ for $1 \mathrm{~h}$ in the presence of $10 \mathrm{mM}$ of phosphate buffer (PB) $\mathrm{pH}$ $7.4 ; 1 \mathrm{mg} / \mathrm{mL}$ of GAA; $20 \mu \mathrm{g} / \mathrm{mL}$ of enzyme; and $10 \mathrm{mM}$ of uridine-diphosphate-glucose (UDP-G). (3) Biotransformation products of the reaction product in (2) by Toruzyme ${ }^{\circledR}$ at $60{ }^{\circ} \mathrm{C}$ for $4 \mathrm{~h}$ in the presence of $50 \mathrm{mM}$ of acetate buffer $\mathrm{pH} 5.0 ; 0.3 \mathrm{KNU} / \mathrm{mL}$ of enzyme and $2 \%$ maltose. (4) The same condition as that of (3) but with $20 \%$ maltose.

To increase the conversion of GAA-15-G into GAA-G2 by Toruzyme ${ }^{\circledR}$, different sugars, sugar concentrations, reaction $\mathrm{pH}$, and reaction temperatures were further evaluated. When using different sugars with $2 \%$ concentration, the highest conversion was observed for the reaction with maltose (Figure 2a). We thus assayed different concentrations of maltose and found that maltose concentration dramatically affected the biotransformation of GAA-15-G by Toruzyme ${ }^{\circledR}$ (Figure 2b). An increase in maltose concentration from $2 \%$ to $20 \%$ resulted in an increase in both conversion and the types of products. Figure 1 (4) shows the HPLC analysis of the reaction products biotransformed from GAA-15-G by Toruzyme ${ }^{\circledR}$ with $20 \%$ maltose, where multiple derivatives, GAA-G2 to GAA-G4, were produced. In addition, conversion was stable between $50^{\circ} \mathrm{C}$ and $60^{\circ} \mathrm{C}$ (Figure 2c) and exhibited optimal transformation activity at $\mathrm{pH} 5$ (Figure $2 \mathrm{~d}$ ) with $0.3 \mathrm{KNU}$ (kilo novo units) $/ \mathrm{mL}$ Toruzyme ${ }^{\circledR}$ and $20 \%$ maltose. Finally, the effects of reaction time on the conversion and the yields of different products were evaluated. The results showed that both the conversion and yields of the products increased quickly during 0 to $4 \mathrm{~h}$, and then reached maximum 
conversion and yields from 4 to $8 \mathrm{~h}$ (Figure 3). In summary, the optimal reaction condition for Toruzyme ${ }^{\circledR}$ catalyzing GAA-15-G was $20 \%$ maltose, pH 5 at $60{ }^{\circ} \mathrm{C}$ for $6 \mathrm{~h}$, where conversion was $58.9 \%$ and the yields of GAA-G2 to GAA-G4 were $27.8 \%, 17.5 \%$, and $7.8 \%$, respectively.

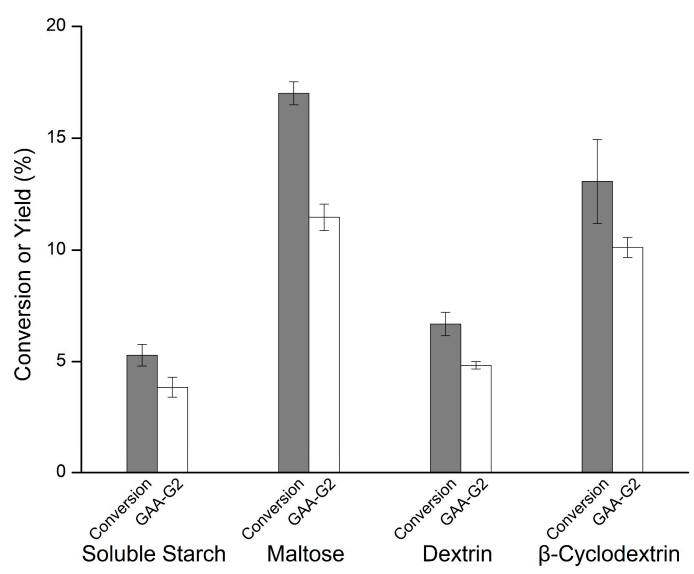

(a)

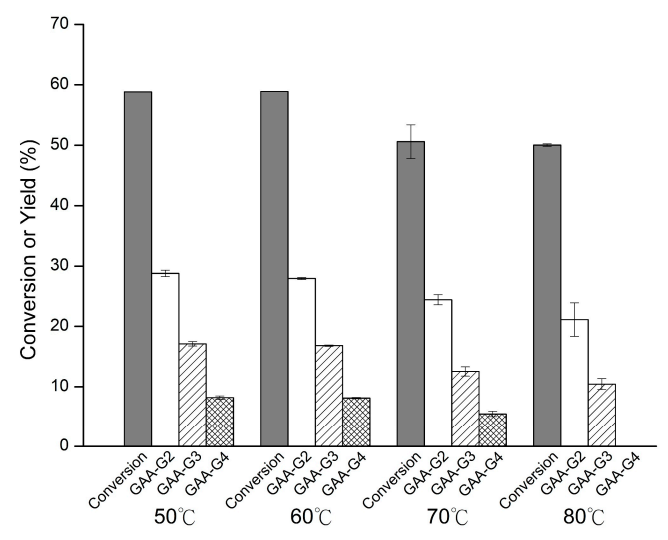

(c)

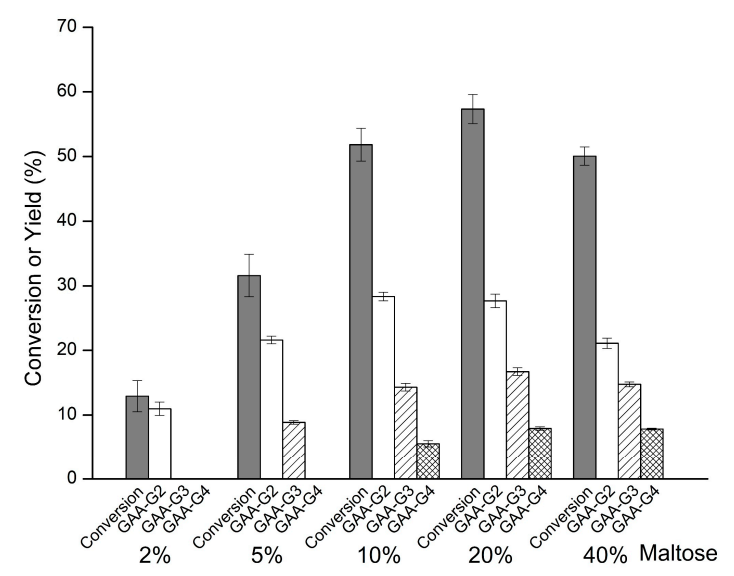

(b)

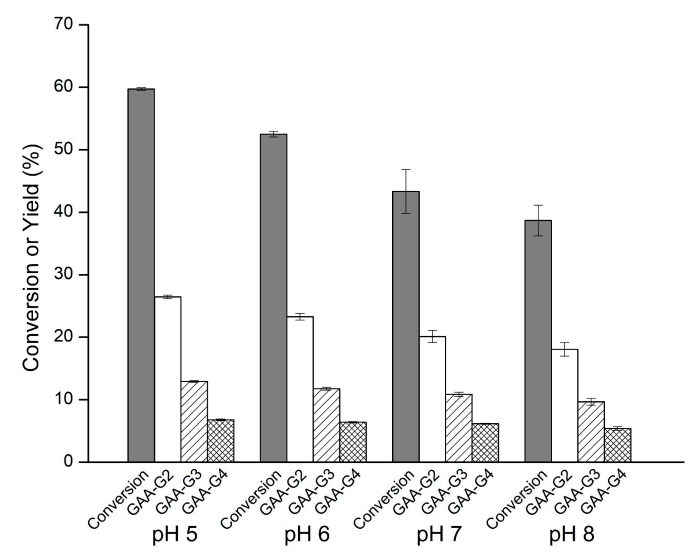

(d)

Figure 2. Effects of different sugars (a), maltose concentrations (b), $\mathrm{pH}(\mathbf{c})$, and temperatures (d) on glycosylation activity of Toruzyme ${ }^{\circledR}$ toward GAA-15-G. The first biotransformation of GAA was performed by $20 \mu \mathrm{g} / \mathrm{mL}$ of BtGT_16345 at $30{ }^{\circ} \mathrm{C}$ for $30 \mathrm{~min}$ in the presence of $10 \mathrm{mM}$ of PB pH 7.4; $1 \mathrm{mg} / \mathrm{mL}$ of GAA; and $10 \mathrm{mM}$ of UDP-G. Then, equal volume of $50 \mathrm{mM}$ of acetate buffer at $\mathrm{pH} 5$ containing $0.3 \mathrm{KNU} / \mathrm{mL}$ Toruzyme ${ }^{\circledR}$ and $2 \%(\mathrm{w} / \mathrm{v})$ of tested sugar was added to start the second biotransformation at $60{ }^{\circ} \mathrm{C}$ for $4 \mathrm{~h}$. The control reaction was conducted without adding Toruzyme ${ }^{\circledR}$. The optimal reaction condition was determined by checking the reaction under different sugars, maltose concentrations, $\mathrm{pH}$ values, and temperature conditions. The conversion was calculated by (1-residue) * $100 \%$, where residue was obtained by dividing the peak area of GAA-15-G in the reaction in the HPLC profile by that of the GAA-15-G in the control reaction. The yields of the products were obtained by dividing the area of the product peak of the reaction in the HPLC profile by that of the GAA-15-G peak at the control reaction. The results are presented as mean values \pm standard deviations $(n=3)$. 


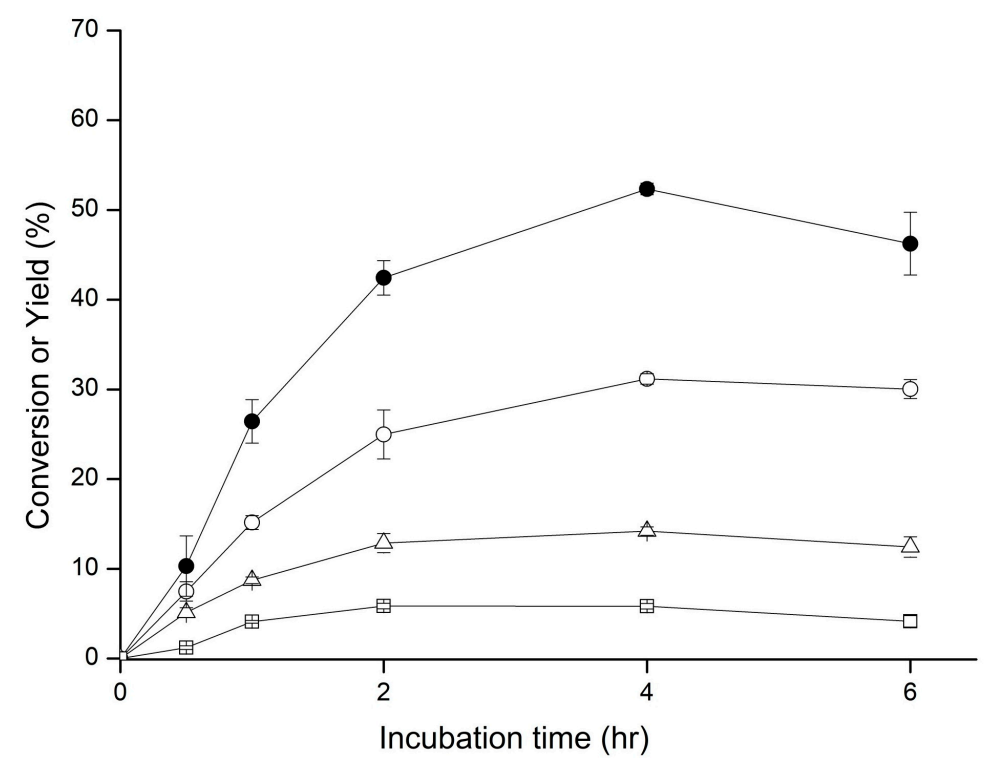

Figure 3. Time course of the conversion and of the products' yields from GAA-15-G biotransformed by Toruzyme ${ }^{\circledR}$. Time course of the conversion (closed circle), and the products' yields, GAA-G2 (open circle), GAA-G3 (open triangle), and GAA-G4 (open square), from the biotransformation of GAA-15-G by $0.3 \mathrm{KNU} / \mathrm{mL}$ Toruzyme ${ }^{\circledR}$ with $20 \%$ of maltose at $\mathrm{pH} 5$ and $60{ }^{\circ} \mathrm{C}$ from 0 to $8 \mathrm{~h}$ calculated as described in Figure 2 was plotted. The results are presented as mean values \pm standard deviations $(n=3)$.

\subsection{Purification and Identification of the Biotransformed Products}

To determine the chemical structures of the products, the reaction was scaled-up to $30 \mathrm{~mL}$, and the products were purified using preparative HPLC method. The molecular weights and the structures of the purified products were then determined by mass and mass-mass spectral analysis. The mass detector showed that the molecular weights $[\mathrm{M}-\mathrm{H}]^{-}$of compounds GAA-G2 to GAA-G4 were 839.5 (Figures S1 and S2), 1001.5 (Figures S3 and S4), and 1163.6 (Figures S5 and S6) m/z, respectively. Therefore, the mass data supported the implication observed in the HPLC profile that Toruzyme ${ }^{\circledR}$ biotransformed GAA saponins by increasing one glucose residue $\left(\mathrm{m} / \mathrm{z}=162,[\text { Glucose-OH] }]^{-}\right)$at a time. Moreover, the mass-mass data also showed the corresponding molecules with glucoside breakdown in each GAA saponin's analysis. In GAA-G2 mass-mass analysis, both GAAglucoside $\left(\mathrm{m} / \mathrm{z} 677.2,[\mathrm{M}-\mathrm{H}]^{-}\right)$and GAA $\left(\mathrm{m} / \mathrm{z} 515.4,[\mathrm{M}-\mathrm{H}]^{-}\right)$were detected (Figure S2); In GAA-G3 mass-mass analysis, GAA-diglucoside ( $\mathrm{m} / \mathrm{z}$ 839.6, $\left.[\mathrm{M}-\mathrm{H}]^{-}\right)$, GAA-glucoside $\left(\mathrm{m} / \mathrm{z}\right.$ 677.3, $\left.[\mathrm{M}-\mathrm{H}]^{-}\right)$, and GAA $\left(\mathrm{m} / \mathrm{z}\right.$ 515.4, $\left.[\mathrm{M}-\mathrm{H}]^{-}\right)$were detected (Figure S4); In GAA-G4 mass-mass analysis, GAA-triglucoside $\left(\mathrm{m} / \mathrm{z}\right.$ 1001.4, $\left.[\mathrm{M}-\mathrm{H}]^{-}\right)$, GAA-diglucoside $(\mathrm{m} / \mathrm{z}$ 839.5, $\left.[\mathrm{M}-\mathrm{H}]^{-}\right)$, GAA-glucoside $\left(\mathrm{m} / \mathrm{z} 677.4,[\mathrm{M}-\mathrm{H}]^{-}\right)$, and GAA $\left(\mathrm{m} / \mathrm{z} 515.2,[\mathrm{M}-\mathrm{H}]^{-}\right)$were detected (Figure S6). Thus, GAA-G2 to GAA-G4 were diglucosyl, triglucosyl, and tetraglucosyl GAA saponins, respectively. The structure of GAA-G2 was further determined by nucleic magnetic resonance (NMR) spectral analysis. The ${ }^{1} \mathrm{H}$ and ${ }^{13} \mathrm{C} N M R$, including distortionless enhancement by polarization transfer (DEPT), heteronuclear single quantum coherence (HSQC), heteronuclear multiple bond connectivity (HMBC), correlation spectroscopy (COSY), and nuclear Overhauser effect spectroscopy (NOESY), spectra were obtained (shown in Figures S7-S13). In addition to the signals of the GAA, fourteen proton signals (from 3.77 to $5.88 \mathrm{ppm}$ ) and twelve carbon signals (from 61.9 to $105.0 \mathrm{ppm}$ ) corresponding to two glucose moiety structures were observed. The first glucosyl moiety connected to GAA was confirmed according to the NOE connectivity between its anomeric proton $\mathrm{H}-1^{\prime}$ at $\delta=4.86(\mathrm{~d}, J=7.9 \mathrm{~Hz})$, which is in $\beta$-configuration, and the $\mathrm{H}-15$ $(\delta=5.34 \mathrm{ppm})$ of GAA, as well as the HMBC cross signals $\mathrm{H}-1^{\prime} / \mathrm{C}-15$ (4.86/82.7 ppm) and $\mathrm{H}-15 / \mathrm{C}-1^{\prime}(5.34 / 105.0 \mathrm{ppm})$. The significant downfield shift of the ${ }^{13} \mathrm{C}$ signal of $\mathrm{C}-4^{\prime}$ indicated the connection of a second glucosyl moiety. The NOE connectivity between $\mathrm{H}-4^{\prime}$ 
$\left(\mathrm{d}=4.30 \mathrm{ppm}\right.$ ) with the anomeric proton $\mathrm{H}-1^{\prime \prime}$ at $\delta=5.88(\mathrm{~d}, J=3.9 \mathrm{~Hz})$, as well as the HMBC cross peaks of H-1" /C-4' (5.88/81.2 ppm) and H-4' /C-1" (4.30/103.0 ppm), confirmed the $\alpha-(1 \rightarrow 4)$ linkage of the second glucosyl moiety. The NMR signals were fully identified and are shown in Table S1. The compound GAA-G2 was thus confirmed as GAA-15-O- $[\alpha-$ glucopyranosyl-( $1 \rightarrow 4)-\beta$-glucopyranoside]. The results showed that the glycosylation of GAA-15-G by Toruzyme ${ }^{\circledR}$ was the same as the starch linkage. Figure 4 summarizes the sequential biotransformation process of GAA by BtGT_16345 and Toruzyme ${ }^{\circledR}$.

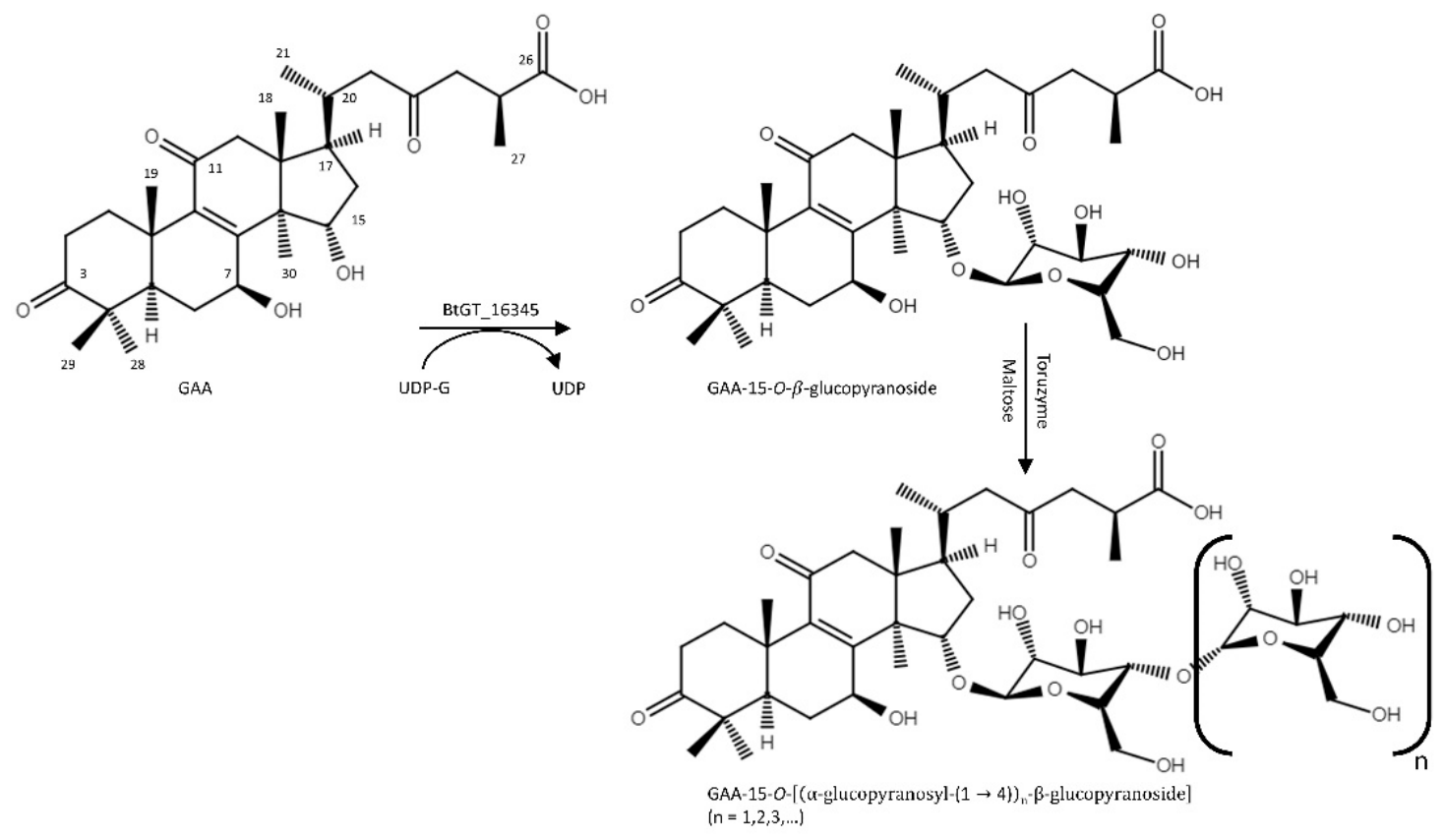

Figure 4. Sequential biotransformation process of GAA by BtGT_16345 and Toruzyme ${ }^{\circledR}$.

\subsection{Determination of Aqueous Solubility of the Products}

It has been reported that glycosylation of small molecules would increase the aqueous solubility of the molecule. Therefore, the aqueous solubility of the major product, GAA-G2, was determined by using the HPLC method. Table 1 shows that the aqueous solubility of GAA-G2 was over the maximal detection $(70,000 \mathrm{mg} / \mathrm{L})$ in this study, which was higher than 4554-fold of that of GAA.

Table 1. Aqueous solubility of ganoderic acid A (GAA) and its derivatives at $25^{\circ} \mathrm{C}$.

\begin{tabular}{cccc}
\hline Compound & Aqueous Solubility (mg/L) & Fold $^{\mathbf{1}}$ & Reference \\
\hline GAA & $15.37 \pm 0.36$ & 1 & {$[35]$} \\
GAA-15-G & $920.17 \pm 44.97$ & 59.9 & {$[35]$} \\
GAA-15,26- & $15,743 \pm 1270.39$ & 1024.4 & {$[35]$} \\
diglucoside & $>70,000$ & $>4554.3$ & This study \\
GAA-G2 &
\end{tabular}

${ }^{1}$ The fold of aqueous solubility of GAA glucoside derivatives is expressed as relative to that of GAA, normalized to 1 .

\section{Discussion}

Glycosylation of small molecules not only increases the aqueous solubility [10-13] but may also improve the bioavailability of the molecule [14,15]. In addition, different types, numbers, and linkage sites of sugars may also affect the bioactivities of the molecule [7-10]. Even though G. lucidum possesses hundreds of triterpenoids, very few triterpenoid saponins have been discovered [20,21]. Thus, applying glycosylation on Ganoderma triterpenoids may be helpful in the synthesis of biomedicine derivatives. 
There are two gene families of enzymes catalyzing the glycosylation of small molecules: GT $[16,17,22,23]$ and GH $[18,19,25]$. Using low-cost sugar as sugar donors on GH enzymes is considered more cost-effective than GTs, which requires expensive sugar donors such as UDP-G. Although some GH13 or GH70 enzymes have been reported to catalyze the glycosylation of simple phenolics or flavonoids $[18,19,25]$, no GHs have been found to catalyze the glycosylation of triterpenoid aglycones yet. This study also showed that none the four selected GH13 enzymes could catalyze the glycosylation of GAA [18,19,25]. Hence, designing synthetic strategies via GH enzymes to catalyze the glycosylation of triterpenoid aglycones has become a valuable strategy.

Previous reports have described the glycosylation of flavonoid glycosides by amylosucrase [33,34] or Toruzyme ${ }^{\circledR}$ [30]; the glycosylation of steroidal saponins by $\alpha$-amylases [26] or Toruzyme ${ }^{\circledR}[26,31]$; and the glycosylation of Ginseng triterpenoid saponin by Toruzyme ${ }^{\circledR}$ [32]. In the present study, only Toruzyme ${ }^{\circledR}$ could biotransform Ganoderma triterpenoid saponin, GAA-15-G (Figure 1). The result revealed that Toruzyme ${ }^{\circledR}$ catalyzed glycosylation toward a broader substrate range than that of amylosucrase or $\alpha$-amylase. In addition, previous studies have shown that Toruzyme ${ }^{\circledR}$ catalyzed the $\alpha-(1 \rightarrow 4)$ glycosylation linkage on the sugar acceptors of flavonoid glucoside [30] or steroidal saponins [26,31]. The result of the present study showing that Toruzyme ${ }^{\circledR}$ catalyzed $\alpha-(1 \rightarrow 4)$ glycosylation linkage on the sugar acceptor of GAA-15-G (Figure 4) was consistent with the previous studies. Meanwhile, other scientists also conducted a similar one-pot enzymatic reaction through cyclodextrin glucanotransferase stepwise with other enzymes to produce novel fine chemicals. Koh et al. combined amylosucrase and cyclodextrin glucanotransferase to produce cyclodextrin from sucrose [36]. Gonzalez-Alfonso et al. also combined cyclodextrin glucanotransferase and amyloglucosidase to produce pterostilbene monoglucoside [28] Shimoda et al. combined a plant glucosyltransferase and cyclodextrin glucanotransferaase to produce resveratrol glucosides [37]. Thus, cyclodextrin glucanotransferase in producing novel glucosylated products could be developed through combinations with other enzymes in the future.

There are several advantages of combining BtGT_16345 and Toruzyme ${ }^{\circledR}$ in catalyzing the glycosylation of triterpenoids. Firstly, most of the microbial GTs proven to catalyze the glycosylation of triterpenoids have less regioselectivity toward the triterpenoid substrates compared with the BtGT_16345 used in the present study. For example, UGT109A1 from Bacillus subtilis catalyzes the glycosylation of ginsenosides at either C-3, C-12, or C-20 [38,39]; $\mathrm{Bs} Y \mathrm{jiC}$ from B. subtilis catalyzed the glycosylation of ginsenosides at either C-3, C-6, C-12, or C-20 [40,41]. In contrast, BtGT_16345 from B. thuringiensis regioselectively catalyzed C-15 glycosylation of GAA among its multiple glycosylation sites [24]. Secondly, present and previous studies all show that Toruzyme ${ }^{\circledR}$ catalyzes chain-growth $\alpha-(1 \rightarrow 4)$ glycosylation linkages toward the sugar acceptor of the saponins [26,30,31]. Accordingly, combining BtGT_16345 and Toruzyme ${ }^{\circledR}$ achieved the specific glycosylation of GAA with maltogenic, maltotriogenic, and so on, sugar moieties. Finally, an additional advantage coming from the combination of a retaining $\alpha$-glycosidase $\left(\right.$ Toruzyme $^{\circledR}$ ) with a glycosyltransferase (BtGT_16345) adding the first sugar unit by a $\beta$ bond is that it generates saponins resistant to $\alpha$-glycosidase, hence stable in the following reaction process. Therefore, the strategy could be applied to other triterpenoids in producing regioselectively polyglycosylated triterpenoid saponins.

According to the literature [26-32], the reaction conditions for transglycosylation catalyzed by Toruzyme ${ }^{\circledR}$, including various sugar donors, pH 5-7, and $50-60{ }^{\circ} \mathrm{C}$, have been assessed. Here, we designed our experiments seeking the optimal reaction conditions based on the literature. First, various sugar donors, including soluble starch, maltose, dextrin, and cyclodextrin, were tested in the reaction conducted by $0.3 \mathrm{KNU} / \mathrm{mL}$ of Toruzyme ${ }^{\circledR}$ in $50 \mathrm{mM}$ acetate buffer of $\mathrm{pH} 5$, at $60^{\circ} \mathrm{C}$, for $4 \mathrm{~h}$. Among these sugar donors, maltose gave the highest conversion. Therefore, different concentrations of maltose were evaluated next in the same conditions mentioned above. Based on the result, the reaction condition with the best conversion using $20 \%(\mathrm{w} / \mathrm{v})$ maltose was conducted, except that 
the reaction temperatures were different. Finally, the reaction buffers with different $\mathrm{pH}$ values were tested in the optimized reaction conditions established above. From the results (Figure 2), the optimal reaction conditions, pH 5 and reaction temperature 50 to $60{ }^{\circ} \mathrm{C}$, are similar to the literature. The only factor has not been assessed previously is that the maltose concentrations in the range of $2-40 \%(\mathrm{w} / \mathrm{v})$ affect significantly the reaction efficiency of Toruzyme ${ }^{\circledR}$. Here, we found that increasing the maltose concentration from $2 \%$ to $20 \%$ would dramatically increase the conversion yields, as well as producing more derivatives during the biotransformation of GAA-15-G by Toruzyme ${ }^{\circledR}$ (Figure 2). The optimal molar ratio between maltose and GAA-15-G is 600 (for $20 \%$ maltose: $584.3 \mathrm{mM}$ of maltose $/ 0.97 \mathrm{mM}$ of GAA-15-G), which was dramatically higher than similar studies using Toruzyme $^{\circledR}$ as a biocatalyst [26-32]. Choung et al. used maltose $(1 \% \mathrm{w} / \mathrm{v}$ and 6.6 molar ratio) as a sugar donor to conduct the glycosylation reaction, where the sugar acceptor was astragalin, a flavonoid glucoside [30]. Zhou et al. [26], Wang et al. [31], and Moon et al. [32] used $0.3-0.7 \%$ dextrin on the glycosylation of steroidal saponins or Ginseng saponins, but the molar ratio between dextrin and the sugar acceptors was below 10. Gonzalez-Alfonso et al. studied the glycosylation of epigallocatechin gallate (EGCG) by Toruzyme ${ }^{\circledR}$ and found that changing the sugar donor (starch) concentration from $1 \%$ to $30 \%$ did not alter the glycosylation activity [27]. The possible reason that previous studies did not find positive effects on Toruzyme ${ }^{\circledR}$ activity by the high concentrations of sugar donors is that starch or dextrin are low-soluble sugars (less than $2 \%$ in our experience). In contrast, maltose is highly soluble, in which its aqueous solubility can reach $40 \%$ or beyond. This explains why the effect of maltose concentration on the glycosylation activity by Toruzyme ${ }^{\circledR}$ could be observed in our study. Our results suggest that high concentrations of maltose can potentially be applied in the glycosylation of small molecules by Toruzyme ${ }^{\circledR}$.

It is well known that glycosylation would increase the aqueous solubility of the modified molecules $[10,13,33]$. This study revealed that the aqueous solubility of the Ganoderma saponin GAA-G2 was over 4554-fold higher than that of GAA, whereas the aqueous solubility of another GAA saponin, GAA-15,26-diglucoside, was previously found to be 1024-fold higher than that of GAA (Table 1) [35]. It is intriguing that the solubility of GAA-15,26-diglucoside was lower than that of GAA-G2 (diglucoside isomer). Nevertheless, the comparison showed that not only the number of side chain sugars but also the position of sugars would affect the aqueous solubility of the modified derivatives.

Herein, a series of Ganoderma triterpenoid saponins were produced in a one-pot reaction by stepwise reactions of BtGT_16345 from Bacillus thuringiensis GA A07 and Toruzyme ${ }^{\circledR}$ from Thermoanaerobacter sp. The produced GAA triterpenoid saponins possess higher aqueous solubility than GAA. The strategy could be applied to other Ganoderma triterpenoids in producing more novel Ganoderma triterpenoid saponins. Moreover, the produced novel Ganoderma saponins might have unique bioactivities that could benefit the medicinal industry.

\section{Materials and Methods}

\subsection{Chemicals and Enzymes}

GAA was purchased from Baoji Herbest Bio-Tech (Xi-An, Shaanxi, China). UDP-glucose was obtained from Cayman Chemical (Ann Arbor, MI, USA). Recombinant BtGT_16345 (GenBank BioProject accession no. PRJNA557365; Genome accession no. CP042270; Protein accession no. QFR29366) [24] and DgAS [12] were obtained from our previous studies. Cyclodextrin glucanotransferase (Toruzyme ${ }^{\circledR} 3.0 \mathrm{~L} ; 3 \mathrm{KNU}$ (kilo novo units)/mL) from Thermoanaerobacter sp. was a product from Novozyme (Bagsvaerd, Denmark) and kindly provided by Trump Chemicals (Taipei, Taiwan). Both $\alpha$-amylases (Sigma 10065 and A3306) were bought from Sigma (St. Louis, MO, USA). The other reagents and solvents used in this study were commercially available. 


\subsection{Biotransformation}

For biotransformation of GAA by $\alpha$-amylase from A. oryzae (Sigma 10065), $50 \mathrm{mM}$ phosphate buffer (PB) of $\mathrm{pH} 6,20 \%$ maltose, $3400 \mathrm{U} / \mathrm{mL}$ enzyme, and $1 \mathrm{mg} / \mathrm{mL}$ of GAA were incubated at $30{ }^{\circ} \mathrm{C}$ for $4 \mathrm{~h}$. For biotransformation of GAA by $\alpha$-amylase from $B$. licheniformis (Sigma A3306), $50 \mathrm{mM} \mathrm{PB}$ of $\mathrm{pH} 6,20 \%$ maltose, 4000 U/mL enzyme, and $1 \mathrm{mg} / \mathrm{mL}$ of GAA were incubated at $60^{\circ} \mathrm{C}$ for $4 \mathrm{~h}$. For biotransformation of GAA by DgAS, $50 \mathrm{mM}$ PB of $\mathrm{pH} 7,20 \%$ sucrose, $10 \mu \mathrm{g} / \mathrm{mL}$ enzyme, and $1 \mathrm{mg} / \mathrm{mL}$ of GAA were incubated at $30^{\circ} \mathrm{C}$ for $4 \mathrm{~h}$. For biotransformation of GAA by Toruzyme ${ }^{\circledR}, 50 \mathrm{mM}$ acetate buffer of $\mathrm{pH}$ $5,20 \%$ maltose, $10 \%$ (v/v) enzyme, and $1 \mathrm{mg} / \mathrm{mL}$ of GAA were incubated at $60{ }^{\circ} \mathrm{C}$ for $4 \mathrm{~h}$. After the reactions, the reaction mixtures were mixed with equal volume of methanol and analyzed with HPLC.

The biotransformation of GAA by the combined actions of BtGT_16345 and Toruzyme ${ }^{\circledR}$ was performed in a one-pot solution via two sequential steps. First, the biotransformation was conducted in $0.1 \mathrm{~mL}$ reaction mixture containing $1 \mathrm{mg} / \mathrm{mL}$ GAA, $15 \mu \mathrm{g} / \mathrm{mL}$ BtGT_16345, $10 \mathrm{mM} \mathrm{MgCl}$, and $10 \mathrm{mM}$ UDP-G at pH 7.4 (10 mM PB). The reaction was performed at $30^{\circ} \mathrm{C}$ for $30 \mathrm{~min}$. Afterwards, the reaction mixture was mixed with equal volume of second reaction buffer containing $2 \%$ different sugar and $0.3 \mathrm{KNU} / \mathrm{mL}$ Toruzyme ${ }^{\circledR}$ in $50 \mathrm{mM}$ of acetate buffer at $\mathrm{pH}$. The second reaction was performed at $60^{\circ} \mathrm{C}$ for $4 \mathrm{~h}$ and then analyzed with HPLC. For optimization experiments of $\mathrm{pH}, 50 \mathrm{mM}$ of acetate buffer ( $\mathrm{pH} 5)$, phosphate buffer ( $\mathrm{pH} 6$ and $\mathrm{pH} 7)$, and Tris buffer $(\mathrm{pH} 8)$ were used. For optimization experiments of sugar concentration, $2-40 \%$ of maltose was used.

\subsection{High-Performance Liquid Chromatography (HPLC)}

HPLC was performed with an Agilent ${ }^{\circledR} 1100$ series HPLC system (Santa Clara, CA, USA) equipped with a gradient pump (Waters 600, Waters, Milford, MA, USA). The stationary phase was a C18 column (Sharpsil H-C18, $5 \mu \mathrm{m}, 4.6$ i.d. $\times 250 \mathrm{~mm}$, Sharpsil, Beijing, China), and the mobile phase was $1 \%$ acetic acid in water (A) and methanol (B). The elution condition was a linear gradient from 0 min with $40 \%$ B to 20 min with $70 \%$ B; isocratic elution from $20 \mathrm{~min}$ to $25 \mathrm{~min}$ with $70 \% \mathrm{~B}$; linear gradient from $25 \mathrm{~min}$ with $70 \% \mathrm{~B}$ to $28 \mathrm{~min}$ with $40 \% \mathrm{~B}$; and isocratic elution from $28 \mathrm{~min}$ to $35 \mathrm{~min}$ with $40 \% \mathrm{~B}$. All elutes were at a flow rate of $1 \mathrm{~mL} / \mathrm{min}$. Sample volume was $10 \mu \mathrm{L}$. The detection condition was set at $254 \mathrm{~nm}$.

\subsection{Purification and Identification of the Glycosylated Products}

First, the reaction mixture ( $30 \mathrm{~mL}$ containing $1 \mathrm{mg} / \mathrm{mL}$ GAA, $15 \mu \mathrm{g} / \mathrm{mL}$ BsGT110, $10 \mathrm{mM}$ UDP-glucose, $10 \mathrm{mM} \mathrm{MgCl} 2,10 \mathrm{mM}$ phosphate buffer at $\mathrm{pH}$ 7.4) was incubated at $30{ }^{\circ} \mathrm{C}$ for $30 \mathrm{~min}$. Next, $30 \mathrm{~mL}$ of $50 \mathrm{mM}$ acetate buffer (pH 5) containing $20 \%$ maltose and $0.3 \mathrm{KNU} / \mathrm{mL}$ Toruzyme ${ }^{\circledR}$ was added into the reaction mixture to start the second biotransformation. After $4 \mathrm{~h}$ incubation at $60^{\circ} \mathrm{C}$, the reaction was stopped by adding $60 \mathrm{~mL}$ of methanol into the mixture. Then, the reaction mixture, $120 \mathrm{~mL}$ with $50 \%$ methanol, was resolved by the preparative YL9100 HPLC system (YoungLin, Gyeonggi-do, Korea). In this system, Inertsil ODS 3 column $(10 \mathrm{~mm}, 20$ i.d. $\times 250 \mathrm{~mm}$, GL Sciences, Eindhoven, The Netherlands) was the stationary phase. The same mobile phase as that in the HPLC system, but with a flow rate of $15 \mathrm{~mL} / \mathrm{min}$ was applied. $5 \mathrm{~mL}$ sample was injected each time and the products were detected by optical absorbance at $254 \mathrm{~nm}$. After products collected, they were concentrated by a vacuum pump then lyophilized by a freeze dryer. Finally, $9.39 \mathrm{mg}$ and $4.41 \mathrm{mg}$ of the products, GAA-G2 and GAA-G3, were purified, while the amount of the purified GAA-G4 was less than $1 \mathrm{mg}$. The chemical structures of the products were determined with mass, mass-mass, and NMR spectral analyses. The Finnigan LCQ Duo mass spectrometer (ThermoQuest Corp., San Jose, CA, USA) with ESI was used for the mass spectral analysis. The Bruker AV-700 NMR spectrometer (Bruker Corp., Billerica, MA, USA) recorded ${ }^{1} \mathrm{H}-$ and ${ }^{13} \mathrm{C}-\mathrm{NMR}$, DEPT, HSQC, HMBC, COSY, and NOESY spectra at ambient temperature. The NMR experiments used standard pulse 
sequences and parameters (Topspin program 4.0), and reported all chemical shifts in parts per million $(\mathrm{ppm}, \delta)$.

\subsection{Determination of Aqueous Solubility of the Glycosylated Products}

Aqueous solubility and stability were assessed with the methods that we used in a previous study [12]. For aqueous solubility assay, $7 \mathrm{mg}$ of GAA-G2 was vortexed in $0.1 \mathrm{~mL}$ of distilled deionized (d.d.) $\mathrm{H}_{2} \mathrm{O}$ for $10 \mathrm{~min}$ at $25^{\circ} \mathrm{C}$ and then centrifuged at $14,000 \times g$. The supernatant was filtrated through a $0.2 \mu$ m nylon membrane, diluted 200 -fold with $50 \%$ of methanol, and then analyzed with HPLC. The concentrations of the tested compounds were calculated based on their peak areas using calibration curves prepared with HPLC analyses of the same compounds dissolved in dimethyl sulfoxide (DMSO). After assay, all GAA-G2 in water was recovered by lyophilization with a freeze dryer and the assay was repeated once.

Supplementary Materials: The following are available online at https:/ /www.mdpi.com/article/10 .3390 / catal11050580/s1, Table S1: NMR spectroscopic data for GAA-G2 in pyridine-d5 (700 MHz). Figure S1: Mass analysis of GAA-G2 at the negative mode. Figure S2: Mass-mass analysis of the $\mathrm{m} / \mathrm{z}$ 839.5 peak of GAA-G2 at the negative mode. Figure S3: Mass analysis of GAA-G3 at the negative mode. Figure S4: Mass-mass analysis of the m/z 1001.5 peak of GAA-G3 at the negative mode. Figure S5: Mass analysis of GAA-G4 at the negative mode. Figure S6: Mass-mass analysis of the $\mathrm{m} / \mathrm{z} 1163.6$ peak of GAA-G4 at the negative mode. Figure S7: The ${ }^{1} \mathrm{H}-\mathrm{NMR}(700 \mathrm{MHz})$ spectrum of GAA-G2 in pyridine-d5. Figure S8: The ${ }^{13} \mathrm{C}-\mathrm{NMR}(176 \mathrm{MHz})$ spectrum of GAA-G2 in pyridine-d5. Figure S9: The Dept-135 spectrum of GAA-G2 in pyridine-d5. Figure S10: The HSQC (600 MHz) spectrum of GAA-G2 in pyridine-d5. Figure S11: The HMBC (700 MHz) spectrum of GAA-G2 in pyridine-d5. Figure S12: The ${ }^{1} \mathrm{H}_{-}{ }^{1} \mathrm{H}$ COSY $(700 \mathrm{MHz})$ spectrum of GAA-G2 in pyridine-d5. Figure S13: The NOESY (700 MHz) spectrum of GAA-G2 in pyridine-d5.

Author Contributions: Conceptualization: T.-S.C.; data curation: T.-S.C. and Y.-L.T.; methodology: T.-S.C., H.-J.T., J.-Y.W., and C.-M.C.; project administration: T.-S.C.; writing—original draft: T.-S.C., Y.-L.T., H.-J.T., and C.-M.C.; writing-review and editing: Y.-W.W., T.-Y.W., and J.-Y.W. All authors have read and agreed to the published version of the manuscript.

Funding: This research was funded by grants from the Ministry of Science and Technology of Taiwan (Project No. MOST 108-2221-E-024-008-MY2).

Acknowledgments: The authors gratefully acknowledge the use of the Superconducting FT NMR Spectrometer AVANCE III HD $700 \mathrm{MHz}$ belonging to the Instrument Center of National Cheng Kung University.

Conflicts of Interest: The authors declare no conflict of interest.

\section{References}

1. Ahmad, M.F. Ganoderma lucidum: Persuasive biologically active constituents and their health endorsement. Biomed. Pharmacother. 2018, 107, 507-519. [CrossRef] [PubMed]

2. $\mathrm{Wu}$, J.-W.; Zhao, W.; Zhong, J.-J. Biotechnological production and application of ganoderic acids. Appl. Microbiol. Biotechnol. 2010, 87, 457-466.

3. Wen, G.; Li, T.; He, H.; Zhou, X.; Zhu, J. Ganoderic acid A inhibits bleomycin-induced lung fibrosis in mice. Pharmarcology 2020, 105, 568-575. [CrossRef] [PubMed]

4. Wan, B.; Li, Y.; Sun, S.; Yang, Y.; Lv, Y.; Wang, L.; Song, M.; Chen, M. Ganoderic acid A attenuates lipopolysaccharide-induced lung injury in mice. Biosci. Rep. 2019, 39, BSR20190301. [CrossRef]

5. Meng, J.; Wang, S.Z.; He, J.Z.; Zhu, S.Z.; Huang, B.Y.; Wang, S.Y.; Li, M.; Zhou, H.; Lin, S.Q.; Yang, B.X. Ganoderic acid A is the effective ingredient of Ganoderma triterpenes in retarding renal cyst development in polycystic kidney disease. Acta Pharmacol. Sin. 2020, 41, 782-790. [CrossRef] [PubMed]

6. Yu, Z.R.; Jia, W.H.; Liu, C.; Wang, H.Q.; Yang, H.G.; He, G.R.; Chen, R.Y.; Du, G.H. Ganoderic acid A protects neural cells against NO stress injury in vitro via stimulating $\beta$ adrenergic receptors. Acta Pharmacol. Sin. 2020, 41, 516-522. [CrossRef]

7. Yao, L.; Lu, J.; Wang, J.; Gao, W.Y. Advances in biosynthesis of triterpenoid saponins in medicinal plants. Chin. J. Nat. Med. 2020, 18, 417-424. [CrossRef]

8. Shi, Z.Y.; Zeng, J.Z.; Wong, A.S.T. Chemical structures and pharmacological profiles of Ginseng saponins. Molecules 2019, $24,2443$. [CrossRef] 
9. Huang, G.; Lv, M.; Hu, J.; Huang, K.; Xu, H. Glycosylation and activities of natural products. Mini Rev. Med. Chem. 2016, 16, 1013-1016. [CrossRef]

10. Shimoda, K.; Hamada, H.; Hamada, H. Synthesis of xylooligosaccharides of daidzein and their anti-oxidant and anti-allergic activities. Int. J. Mol. Sci. 2011, 12, 5616-5625. [CrossRef]

11. Chiang, C.M.; Wang, T.Y.; Yang, S.Y.; Wu, J.Y.; Chang, T.S. Production of new isoflavone glucosides from glycosylation of 8-hydroxydaidzein by glycosyltransferase from Bacillus subtilis ATCC 6633. Catalysts 2018, 8, 387. [CrossRef]

12. Chang, T.S.; Wang, T.Y.; Yang, S.Y.; Kao, Y.H.; Wu, J.Y.; Chiang, C.M. Potential industrial production of a well-soluble, alkalinestable, and anti-inflammatory isoflavone glucoside from 8-hydroxydaidzein glucosylated by recombinant amylosucrase of Deinococcus geothermalis. Molecules 2019, 24, 2236. [CrossRef]

13. Li, Y.; Liu, L.H.; Yu, X.Q.; Zhang, Y.X.; Yang, J.W.; Hu, X.Q.; Zhang, H.B. Transglycosylation improved caffeic acid phenethyl ester anti-inflammatory activity and water solubility by Leuconostoc mesenteroides dextransucrase. J. Agric. Food Chem. 2019, 67, 4505-4512. [CrossRef]

14. Zhao, J.; Yang, J.; Xie, Y. Improvement strategies for the oral bioavailability of poorly water-soluble flavonoids: An overview. Int. J. Pharm. 2019, 570, 118642. [CrossRef]

15. Fu, J.; Wu, Z.; Zhang, L. Clinical applications of the naturally occurring or synthetic glycosylated low molecular weight. Prog. Mol. Biol. Transl. Sci. 2019, 163, 487-522.

16. Mestrom, L.; Przypis, M.; Kowalczykiewicz, D.; Pollender, A.; Kumpf, A.; Marsden, S.R.; Bento, I.; Jarzebski, A.B.; Szymanska, K.; Chrusciel, A.; et al. Leloir glycosyltransferases in applied biocatalysis: A multidisciplinary approach. Int. J. Mol. Sci. 2019, 20, 5263. [CrossRef] [PubMed]

17. Tiwari, P.; Sangwan, R.S.; Sangwan, N.S. Plant secondary metabolism linked glycosyltransferases: An update on expanding knowledge and scopes. Biotechnol. Adv. 2016, 34, 716-739. [CrossRef] [PubMed]

18. Hofer, B. Recent developments in the enzymatic O-glycosylation of flavonoids. Appl. Microbiol. Biotechnol. 2016, 100, 4269-4281. [CrossRef]

19. Sordon, S.; Poplonski, J.; Huszcza, E. Microbial glycosylation of flavonoids. Pol. J. Microbiol. 2016, 65, 137-151. [CrossRef] [PubMed]

20. Xia, Q.; Zhang, H.; Sun, X.; Zhao, H.; Wu, L.; Zhu, D.; Yang, G.; Shao, Y.; Zhang, X.; Mao, X.; et al. A comprehensive review of the structure elucidation and biological activity of triterpenoids from Ganoderma spp. Molecules 2014, 19, 17478-17535. [CrossRef]

21. Yang, Y.; Zhang, H.; Zuo, J.; Gon, X.; Yi, F.; Zhu, W.; Li, L. Advances in research on the active constituents and physiological effects of Ganoderma lucidum. Biomed. Dermatol. 2019, 3, 6. [CrossRef]

22. Zhang, P.; Zhang, Z.; Zhang, L.; Wang, J.; Wu, C. Glycosyltransferase GT1 family: Phylogenetic distribution, substrates coverage, and representative structural features. Comput. Struct. Biotechnol. J. 2020, 18, 1383-1390. [CrossRef]

23. Chang, T.S.; Wang, T.Y.; Chiang, C.M.; Lin, Y.J.; Chen, H.L.; Wu, Y.W.; Ting, H.J.; Wu, J.Y. Biotransformation of celastrol to a novel, well-soluble, low-toxic and anti-oxidative celastrol-29-O- $\beta$-glucoside by Bacillus glycosyltransferases. J. Biotech. Bioeng. 2021, 131, 176-182.

24. Chang, T.S.; Wang, T.Y.; Hsueh, T.Y.; Lee, Y.W.; Chuang, H.M.; Cai, W.X.; Wu, J.Y.; Chiang, C.M.; Wu, Y.W. A genome-centric approach reveals a novel glycosyltransferase from the GA A07 strain of Bacillus thuringiensis responsible for catalyzing 15-Oglycosylation of ganoderic acid A. Int. J. Mol. Sci. 2019, 20, 5192. [CrossRef] [PubMed]

25. Moulis, C.; Guieysse, D.; Morel, S.; Severac, E.; Remaud-Simeon, M. Natural and engineered transglycosylases: Green tools for the enzyme-based synthesis of glycoproducts. Curr. Opin. Chem. Biol. 2021, 61, 96-106. [CrossRef]

26. Zhou, W.B.; Feng, B.; Huang, H.Z.; Qin, Y.J.; Wang, Y.Z.; Kang, L.P.; Zhao, Y.; Wang, X.N.; Cai, Y.; Tan, D.W.; et al. Enzymatic synthesis of $\alpha$-glucosyl-timosaponin BII catalyzed by the extremely thermophilic enzyme: Toruzyme 3.0 L. Carbohyd. Res. 2010, 345, 1752-1759. [CrossRef] [PubMed]

27. Gonzalez-Alfonso, J.L.; Leemans, L.; Poveda, A.; Jimenez-Barbero, J.; Ballesteros, A.O.; Plou, F.J. Efficient $\alpha$-glucosylation of epigallocatechin catalyzed by cyclodextrin glucanotransferase from Thermoanaerobacter species. J. Agric. Food Chem. 2018, 66, 7402-7408. [CrossRef] [PubMed]

28. Gonzalez-Alfonso, J.L.; Rodrigo-Frutos, D.; Belmonte-Reche, E.; Penalver, P.; Poveda, A.; Jimenez-Barbero, J.; Ballesteros, A.O.; Hirose, Y.; Polaina, J.; Morales, J.C.; et al. Enzymatic synthesis of a novel pterostilbene $\alpha$-glucoside by the combination of cyclodextrin glucanotransferase and amyloglucosidase. Molecules 2018, 23, 1271. [CrossRef] [PubMed]

29. González-Alfonso, J.L.; Miguez, N.; Padilla, D.; Leemans, L.; Poveda, A.; Jiménez-Barbero, J.; Ballesteros, A.O.; Sandoval, G.; Plou, F.J. Optimization of regioselective $\alpha$-glucosylation of hesperetin catalyzed by cyclodextrin glucanotransferase. Molecules 2018, 23, 2885. [CrossRef]

30. Choung, W.J.; Hwang, S.H.; Ko, D.S.; Kim, S.B.; Kim, S.H.; Jeon, S.H.; Choi, H.D.; Lim, S.S.; Shim, J.H. Enzymatic synthesis of a novel kaempferol-3-O- $\beta$-D-glucopyranosyl-(1-4)-O- $\alpha$-D-glucopyranoside using cyclodextrin glucanotransferase and its inhibitory effects on aldose reductase, inflammation, and oxidative stress. J. Agric. Food Chem. 2017, 65, 2760-2767. [CrossRef]

31. Wang, Y.Z.; Feng, B.; Huang, H.Z.; Kang, L.P.; Cong, Y.; Zhou, W.B.; Zou, P.; Cong, Y.W.; Spng, X.B.; Ma, B.P. Glucosylation of steroidal saponins by cyclodextrin glucanotransferase. Plan. Med. 2010, 76, 1724-1731. [CrossRef] [PubMed]

32. Moon, S.S.; Lee, H.J.; Mathiyalagan, R.; Kim, Y.J.; Yang, D.U.; Lee, D.Y.; Min, J.W.; Jimenez, Z.; Yang, D.C. Synthesis of a novel $\alpha$-glucosyl ginsenoside F1 by cyclodextrin glucanotransferase and its in vitro cosmetic applications. Biomolecules $2018,8,142$. [CrossRef] [PubMed] 
33. Rha, C.S.; Kim, E.R.; Kim, Y.J.; Jug, Y.S.; Kim, D.O.; Park, C.S. Simple and efficient production of highly soluble daidzin glycosides by amylosucrase from Deinococcus geothermalis. J. Agric. Food Chem. 2019, 67, 12824-12832. [CrossRef] [PubMed]

34. Rha, C.S.; Choi, J.M.; Jung, Y.S.; Kim, E.R.; Ko, M.J.; Seo, D.H.; Kim, D.O.; Park, C.S. High-efficiency enzymatic production of $\alpha$-isoquercitrin glucosides by amylosucrase from Deinococcus geothermalis. Enz. Micro. Technol. 2019, 120, 84-90. [CrossRef]

35. Chang, T.S.; Chiang, C.M.; Wu, J.Y.; Tsai, Y.L.; Ting, H.J. Production of a new triterpenoid disaccharide saponin from sequential glycosylation of ganoderic acid A by two novel Bacillus glycosyltransferases. Biosci. Biotechnol. Biochem. 2021, 85, 687-690. [CrossRef]

36. Koh, D.W.; Park, M.O.; Choi, S.W.; Lee, B.H.; Yoo, S.H. Efficient biocatalytic production of cyclodextrins by combined action of amylosucrase and cyclodextrin glucanotransferase. J. Agric. Food Chem. 2016, 64, 4371-4375. [CrossRef]

37. Shimoda, K.; Kubota, N.; Hamada, H.; Hamada, H. Synthesis of resveratrol glycosides by plant glucosyltransferase and cyclodextrin glucanotransferase and their neuroprotective activity. Nat. Prod. Commun. 2015, 10, 995-996. [CrossRef]

38. Zhang, T.; Gong, T.; Hu, Z.; Gu, A.; Yang, J.; Zhu, P. Enzymatic synthesis of unnatural ginsenosides using a promiscuous UDP-glucosyltransferase from Bacillus subtilis. Molecules 2018, 23, 2797. [CrossRef]

39. Liang, H.; Hu, Z.; Zhang, T.; Gong, T.; Chen, J.; Zhu, P.; Li, Y.; Yang, J. Production of a bioactive unnatural ginsenoside by metabolically engineered yeasts based on a new UDP-glycosyltransferase from Bacillus subtilis. Metab. Eng. 2017, 44, 60-69. [CrossRef]

40. Dai, L.; Li, J.; Yang, J.; Zhu, Y.; Men, Y.; Zeng, Y.; Cai, Y.; Dong, C.; Dai, Z.; Zhang, X.; et al. Use of a promiscuous glycosyltransferase from Bacillus subtilis 168 for the enzymatic synthesis of novel protopanaxatriol-type Ginsenosides. J. Agric. Food. Chem. 2018, 66, 943-949. [CrossRef] [PubMed]

41. Yu, L.; Chen, Y.; Shi, J.; Wang, R.; Yang, Y.; Yang, L.; Zhao, S.; Wang, Z. Biosynthesis of rare 20(R)-protopanaxadiol/protopanaxatriol type ginsenosides through Escherichia coli engineered with uridine diphosphate glycosyltransferase genes. J. Ginseng Res. 2019, 43, 116-124. [CrossRef] [PubMed] 